\title{
Decontamination Measures for Fukushima Prefecture
}

\section{-Fukushima Prefecture Measures for Promoting Decontamination-}

\author{
Decontamination Division, Living Environment Department, \\ Prefectural Government of Fukushima, Kouzou Endo
}

\begin{abstract}
Fukushima Prefecture is still saddled with a huge number of problems due to the damage caused by the Fukushima Daiichi Nuclear Power Plant Accident in the aftermath of the Great East Japan Earthquake. One of the most pressing tasks that it faces is to carry out decontamination work for the radioactive materials released during the accident. This commentary explains how the prefectural government of Fukushima is currently assisting municipalities to facilitate this decontamination work through three main pillars of activities: (1) accelerating the training of operators and other staff; (2) boosting technical assistance; and (3) promoting understanding (and participation) among local residents.
\end{abstract}

\section{Current Situation in Fukushima Prefecture}

At present, 40 municipalities in the prefecture have been designated by the Ministry of the Environment (MOE) as intensive contamination survey areas. These municipalities have an average hourly radiation dose of at least $0.23 \mu \mathrm{Sv}$ ( $1 \mathrm{mSv}$ per year), but municipalities that have been designated as special decontamination areas (i.e., areas in which decontamination work is conducted by the national government) are excluded. Of these 40 municipalities, 36 have already developed decontamination plans. The remaining four municipalities, which have a relatively low dose, are considering whether they should formulate such plans despite having been designated as intensive contamination survey areas (Figure 1).

\section{Framework for Facilitating Decontamination}

In intensive contamination survey areas, municipalities have been taking a leading role in the conducting of decontamination work following the full enforcement of the Act on Special Measures Concerning the Handling of Pollution by Radioactive Materials on January 1, 2012.

DOI : 10.15669/fukushimainsights.Vol.2.31

(C) 2021 Atomic Energy Society of Japan. All rights reserved.

Originally published in Journal of the Atomic Energy Society of Japan (ISSN 1882-2606), Vol. 55, No. 5, p. 289-291 (2013)

in Japanese. (Japanese version accepted: March 4, 2013) 


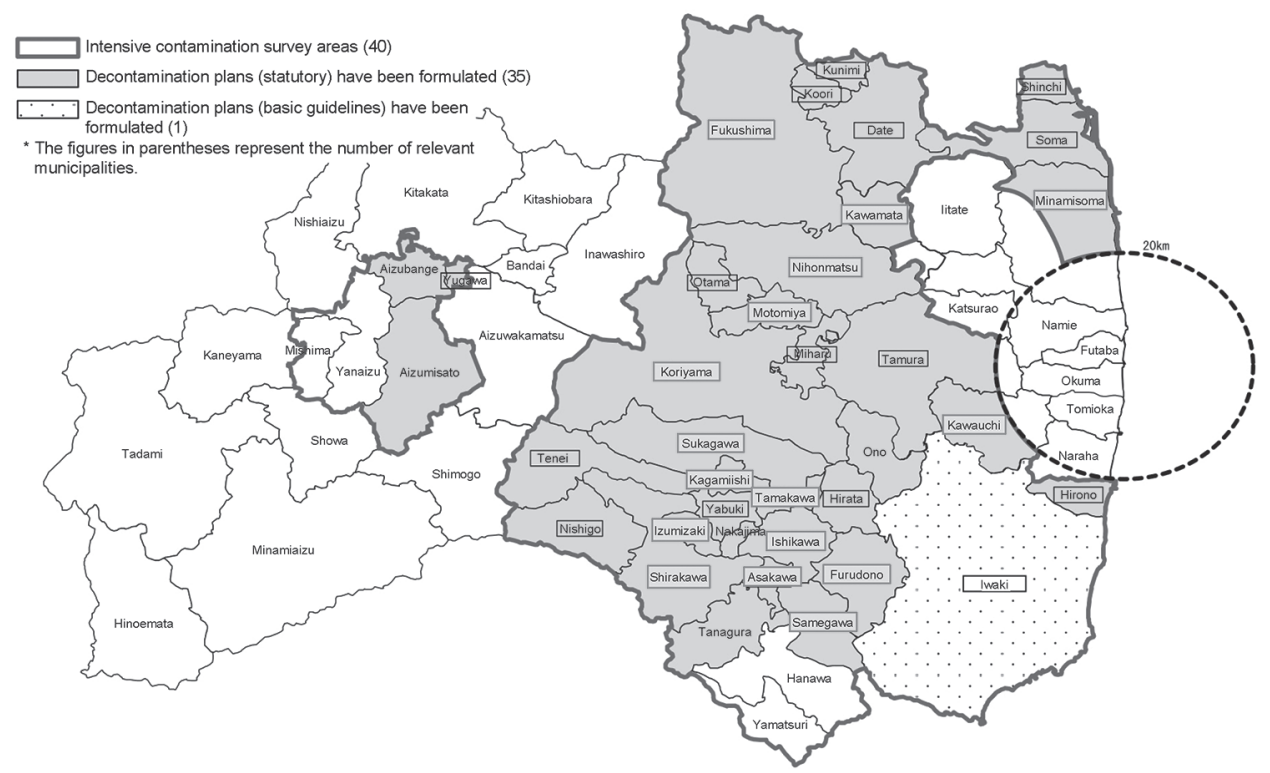

Figure 1 Municipalities designated as intensive contamination survey areas pursuant to the Act on Special Measures and the status of their decontamination plans

To facilitate this work, the prefectural government has established three main pillars of activities: (1) accelerating the training of operators and other staff; (2) boosting technical assistance; and (3) promoting understanding (and participation) among local residents.

\section{Accelerating the Training of Operators and Other Staff}

The training of operators is imperative for full-fledged decontamination efforts. The prefectural government of Fukushima organizes workshops (Figure 2) to allow those engaged in decontamination work to acquire the basic knowledge and skills required.

In FY2011, 15 workshops were held for more than 3,300 trainees from October 2011 to March 2012. In addition, 32 workshops on radiation and decontamination were held in the relevant areas for more than 2,000 leaders of the radiation measurement and decontamination activities.

From FY2012, decontamination workshops were expanded to offer three courses. The first course was held for those actually performing the decontamination work in the same manner as the workshops held in FY2011. In Fukushima Prefecture, 4,443 decontamination workers completed this course.

The second course was held for the on-site leaders and supervisors of decontamination work. This training course was completed by 1,913 people.

The third course was held for operational managers in light of the shortage of supervisors with specialized knowledge. The 1,390 people who completed this training course will assist in supervising any decontamination work that is outsourced by the municipalities.

Training courses for personnel involved in decontamination work will also be held in FY2013. 


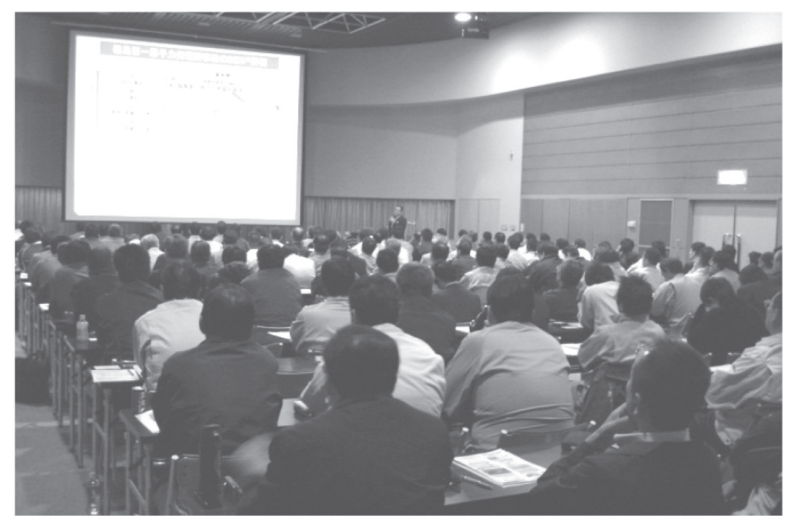

Figure 2 Attendees at a decontamination workshop

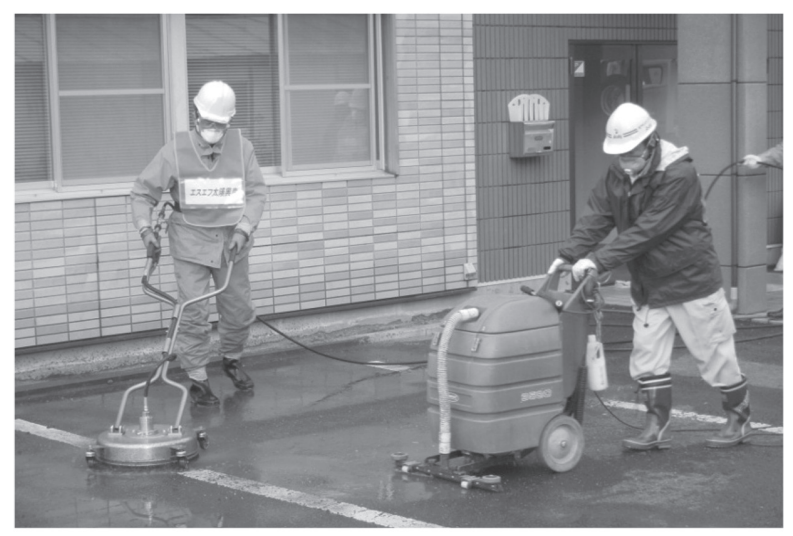

Figure 3 Demonstration of a decontamination technology

\section{Boosting Technical Assistance}

\section{(1) Technical demonstrations}

Technical demonstrations have been held since FY2011 to promote the development of more effective and efficient technologies. To this end, the prefectural government issues calls for proposals from the private sector, universities, research institutes, and so forth. The prefectural government evaluates their technologies by comparing the radiation dose before and after the decontamination work was conducted (Figure 3). In FY2011, 20 of the 177 proposed projects were selected for field trials. The results were announced in March 2012. In FY2012, two calls for proposals were issued. For field trials, 12 of the 98 proposals were chosen in the first round and six of the 32 proposals were chosen in the second round. Technical demonstrations will also be conducted in FY2013. To encourage the application of more effective and efficient decontamination technologies, the prefectural government subsidizes the costs incurred by municipalities in the conducting of demonstration tests to explore new decontamination technologies and methods.

\section{(2) Technical guidelines for decontamination work}

Examples of the contracting procedures for the outsourcing of decontamination work were compiled in December 2011. In January 2012, technical guidelines for decontamination work were developed as a compilation of the specific steps, methods, management standards, and 
all other requirements that apply to decontamination sites.

Samples of common templates for decontamination work were prepared in July, while samples of estimation standards for decontamination work were prepared in August. These samples were subsequently provided to the relevant municipalities.

These documents will be revised to help municipalities outsource decontamination work and manage its implementation.

\section{(3) Decontamination Information Plaza}

In January 2012, the prefectural government established the Decontamination Information Plaza, which is jointly operated with the MOE's Fukushima Office for Environmental Restoration. The Decontamination Information Plaza provides information on decontamination matters in partnership with the Japan Atomic Energy Agency (JAEA) and the Atomic Energy Society of Japan (AESJ). Such information includes details on the latest technologies and equipment as well as the progress made in decontamination work.

The Decontamination Information Plaza uses intuitive exhibits to explain decontamination. It also holds symposiums and workshops for children and their parents to gain a wider public understanding of the impact of radioactivity and the necessary countermeasures.

Furthermore, about 80 volunteer experts are registered with the Decontamination Information Plaza. These experts are dispatched as necessary to offer technical advice to municipalities.

\section{Promoting Understanding among Local Residents}

\section{(1) Community discussion forums}

The understanding of Fukushima Prefecture residents is vital for the conducting of decontamination work. Therefore, the prefectural government has been working with the AESJ since FY2011 to hold forums in many places with the aim of promoting greater understanding of radiation and decontamination.

Each forum consists of lectures and discussion sessions. Participants are invited to exchange their views on how the decontamination work is being conducted and how their health is being affected.

The first forum was held in November 2011. In total, four forums were held in various parts of Fukushima Prefecture in FY2011 and a further five forums were held in FY2012.

The prefecture also supports the briefing sessions that municipalities hold for residents by dispatching experts.

\section{(2) Study tours of temporary storage yards}

For progress to be made in decontamination work, temporary storage yards are needed for the storage of removed soil and other waste. However, securing such space can prove problematic due to a lack of understanding from local residents. One of the main reasons for this is concerns over the safety of temporary storage yards. Accordingly, the prefectural government has been conducting study tours since July 2012 in collaboration with the JAEA and municipalities that have already established such yards. In these hands-on study tours, visitors get to learn how these yards are structured, maintained, and managed. They can also measure the air dose rate for themselves (Figure 4).

The prefectural government also supports the briefing sessions that municipalities hold for residents by dispatching experts. 


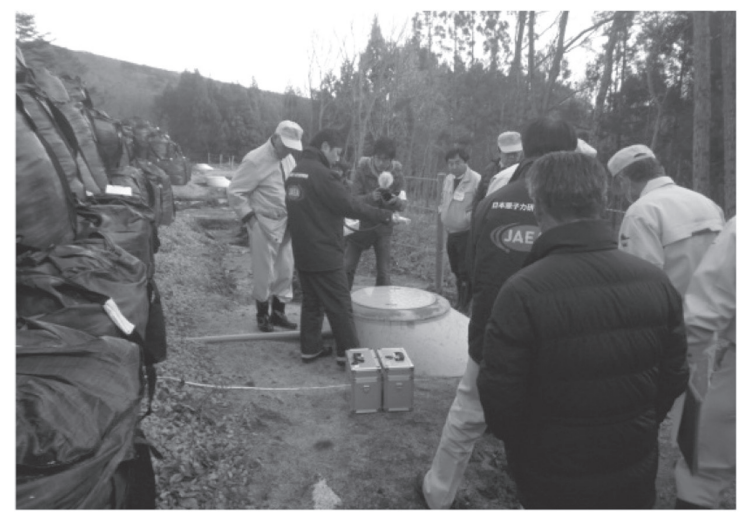

Figure 4 Staff conduct dose measurements during a study tour at a temporary storage yard

\section{(3) Assistance in reducing the radiation dose}

The prefectural government subsidizes the costs incurred by neighborhood associations, parent teacher associations, and other community-based organizations in conducting voluntary activities to reduce radiation dose for children on their ways to schools, as well as in parks and other spaces they usually spend time. Examples of such activities include measuring the air dose rate and conducting spot decontamination of road ditches. In total, 3,091 groups from 44 municipalities benefited from such subsidies in FY2011, and 1,515 groups from 31 municipalities are expected to benefit in FY2012.

\section{Progress Made in Decontamination Work and Challenges Ahead}

\section{Progress Made in Decontamination}

As of January 2013, 35 of the 36 municipalities that had already formulated decontamination plans have outsourced decontamination work. A comparison with the planned numbers reveals that decontamination has been outsourced for 63,328 of the 80,419 houses, 3,475 of the 3,739 public facilities, $2,159 \mathrm{~km}$ of the $2,895 \mathrm{~km}$ of roads, 20,943 ha of the 25,845 ha of farmland, and 739 ha of the roughly 4,090 ha of forests in living areas.

\section{Decontamination Efforts by Municipalities and Challenges Ahead}

\section{(1) Securing space for temporary storage yards}

One major obstacle to conducting decontamination work is the difficulty involved in securing space for temporary storage yards. The prefectural government aims to dispatch experts and personnel to hold briefing sessions for local community members in an effort to gain their understanding. Furthermore, to establish more temporary storage yards, the prefectural government will work with municipalities to present examples of advanced solutions and conduct study tours.

(2) Assistance for municipalities in outsourcing decontamination and related work

Among the other challenges that they face, municipalities have a shortage of personnel 
with specialized knowledge in relation to the outsourcing and supervising of decontamination work. To address this challenge, the prefectural government will prepare samples of standard templates and estimation standards for the outsourcing of decontamination work, revise their technical guidelines as necessary, continue to hold briefing sessions and offer on-site counseling services, train supervisors at decontamination workshops, and dispatch trained experts.

\section{(3) Training and recruitment of decontamination operators}

As the decontamination work conducted by the respective municipalities gathers pace, there are growing concerns about the shortage of decontamination operators. Therefore, the prefectural government will continue to hold decontamination workshops to train more decontamination workers and supervisors. It will also help facilitate cooperation among local operators to increase their decontamination capacity and workforce.

\section{(4) Swift and flexible provision of decontamination subsidies}

During the ongoing decontamination work, the methods specified in the guidelines issued by the national government have often proven unable to reduce the radiation dose as expected. Although more effective methods are required, preferential financial measures only support the methods specified in the national guidelines or methods that have been approved after consultation with the national government. To facilitate progress in the decontamination work, the prefectural government will strive to establish a more flexible subsidy system to promote the use of proven decontamination methods according to local realities.

\section{Conclusions}

Almost 2 years have passed since the accident occurred on March 11, 2011. Decontamination work has been conducted through a process of trial and error, but this work must be accelerated to support early recovery and reconstruction. We would like to express our deep gratitude for the many different types of assistance that we have received from various people throughout the country to date and for all future assistance. 